\title{
Detection of lower levels of SNAP25 using multiple microarray systems and its functional significance in medulloblastoma
}

\author{
CHI-JUNG HUANG ${ }^{1,2}$, CHIA-LONG LEE ${ }^{3,4}$, CHIH-YI LIU ${ }^{5}$, SHIH-HUNG HUANG ${ }^{6}$, JIA-WOEI HOU ${ }^{7}$, \\ YI-HOU CHEN ${ }^{2}$, CHIH-CHENG CHIEN ${ }^{2,8,9}$, CHIH-MING HO ${ }^{2,3,9,10}$, \\ WEN-CHENG $\mathrm{LO}^{3,11^{*}}$ and $\mathrm{KUN}-\mathrm{LONG} \mathrm{HUNG}^{7,9^{*}}$ \\ ${ }^{1}$ Department of Biochemistry, National Defense Medical Center, Taipei $11490 ;{ }^{2}$ Department of Medical Research, \\ Cathay General Hospital, Taipei 10630; ${ }^{3}$ School of Medicine, College of Medicine, Taipei Medical University, \\ Taipei 11031; ${ }^{4}$ Department of Internal Medicine, Cathay General Hospital, Taipei 10630; ${ }^{5}$ Department of Pathology, \\ Sijhih Cathay General Hospital, New Taipei 22174; Departments of ${ }^{6}$ Pathology, ${ }^{7}$ Pediatrics and \\ ${ }^{8}$ Anesthesiology, Cathay General Hospital, Taipei 10630; ${ }^{9}$ School of Medicine, Fu Jen Catholic University, \\ New Taipei 24205; ${ }^{10}$ Department of Obstetrics and Gynecology, Cathay General Hospital, Taipei 10630; \\ ${ }^{11}$ Department of Neurosurgery, Taipei Medical University Hospital, Taipei 11031, Taiwan, R.O.C.
}

Received September 11, 2015; Accepted March 9, 2017

DOI: $10.3892 /$ ijmm.2017.2925

\begin{abstract}
Medulloblastoma (MB) is the most common pediatric malignant brain tumor and patients with high-risk or recurrent MB respond poorly to current therapies, and have a higher related mortality. For this reason, potential molecules related to MB need be identified in order to develop targets for the development of novel therapeutics. In the present study, we compared MB microarray data obtained using different microarray systems and significant targets were selected by gene annotation and enrichment analysis. Genes for soluble $N$-ethylmaleimide-sensitive factor attachment protein receptors (SNAREs) annotated with the function 'vesicle' were
\end{abstract}

Correspondence to: Dr Wen-Cheng Lo, Department of Neurosurgery, Taipei Medical University Hospital, 252 Wuxing Street, Xinyi, Taipei 11031, Taiwan, R.O.C.

E-mail:1060712@yahoo.com.tw

Dr Kun-Long Hung, Department of Pediatrics, Cathay General Hospital, Sec. 4, 280 Renai Road, Daan, Taipei 10630, Taiwan, R.O.C. E-mail: klhung@cgh.org.tw

${ }^{*}$ Contributed equally

Abbreviations: MB, medulloblastoma; SNAREs, soluble $N$-ethylmaleimide-sensitive factor attachment protein receptors; SNAP25, synaptosomal-associated protein 25; Ara-C, arabinofuranosyl cytidine; GEO, Gene Expression Omnibus; GO, Gene Ontology; RT-qPCR, reverse transcription-quantitative polymerase chain reaction; SDS, sodium dodecyl sulfate; HRP, horseradish peroxidase; GFP, green fluorescent protein

Key words: medulloblastoma, Gene Expression Omnibus, dendrite density, arabinofuranosyl cytidine, synaptosomal-associated protein 25 identified and one of these proteins, synaptosomal-associated protein 25 (SNAP25), was found to have significantly lower expression levels in MB. In addition, SNAP25 was detected in a very low number of MB cells as shown by western blot analysis and immunohistochemical analyses of archived and formalin-fixed/paraffin-embedded human MB specimens. We found that SNAP25 altered the morphology and the chemotherapeutic effects of arabinofuranosyl cytidine (Ara-C) on SNAP25-expressing MB cells. On the whole, our data indicate that the expression of SNAP25 is crucial for dendrite formation and is associated with the effects of targeted chemotherapy. The detection of SNAP25 expression in MB cells may thus be essential for the chemotherapeutic application of Ara-C.

\section{Introduction}

Medulloblastoma (MB) is the most common pediatric malignant brain tumor. Historically, MB has been classified into many variants based on its histopathology and cytogenetic biomarkers (1). Different pathways have been implicated in the development of MB and the regulation of the malignant phenotype of MB cells (2-5). Patients with high-risk or recurrent $\mathrm{MB}$ respond poorly to current therapies and they exhibit a higher related mortality (6). Thus, promising clinical targets are required for MB to facilitate the development of novel therapeutics (7).

At present, several targeted molecular therapies are under clinical investigation in patients with MB $(6,8)$. To further understand this malignant disease, high-throughput and genome-wide microarrays have been applied for molecular classification (9), thereby providing novel insight into the underlying biological mechanisms of MB (10). Various cell lines are available for use as experimental models of this neoplastic brain disease (11). Genetic data related to MB are available in an international functional genomics data repository, i.e., the Gene Expression Omnibus (GEO), which were 
derived from the MB cell line, Daoy $(12,13)$. Thus, the study of a combination of genomic scale analyses of the data available in GEO and other whole-genome microarrays may facilitate the identification of underlying biomarkers, which may provide insight into the pathogenesis of brain tumors (14-16).

In the present study, various MB microarray data were extracted and compared. Significant genes that had similar expression patterns in MB according to different microarray systems were selected following gene annotation. Enrichment analysis of the gene set was also performed to elucidate the biological pathways and processes that are affected in patients with MB. Archived and formalin-fixed/paraffin-embedded human MB specimens were also used to validate the significant candidates. A crucial molecular pathway related to MB was identified by this whole-genome survey.

\section{Materials and methods}

Patients and MB cell lines. The archived specimens were derived from previously formalin-fixed/paraffin-embedded biopsies, which were confirmed as MB by the Department of Pathology at Cathay General Hospital, Taipei, Taiwan, and their characteristics are described in Table I. The Institutional Review Board of Cathay General Hospital approved this study. Written form of consent was obtained from the participants or their guardians. MB cell lines, i.e., Daoy (HTB-186 $\left.{ }^{\mathrm{TM}}\right)$, D341 Med (HTB-187 ${ }^{\mathrm{TM}}$ ) and VGH-Med (60375), were purchased from the American Type Culture Collection (Manassas, VA, USA) and the Bioresource Collection and Research Center (Hsinchu, Taiwan). All the cultured cells were maintained in the indicated medium with $10 \%$ (for Daoy) or 20\% (for D341 Med and VGH-Med) fetal bovine serum (Biological Industries, Kibbutz Beit Haemek, Israel) according to routine protocols. Briefly, the adherent Daoy and the suspended D341 Med cells were cultivated in Eagle's minimum essential medium (Cat. no. 41500-034), whereas the adherent VGH-Med cells were cultured in Dulbecco's modified Eagle's medium (12100-046) (both from Life Technologies, Grand Island, NY, USA).

Significantly and differentially expressed genes in MB according to microarray hybridizations. Different microarray systems were used in the analyses, as shown in Fig. 1. Briefly, 15 (GSE7578) and 3 (GSE22139) expression datasets for Daoy cells (from accession series GSE7578 and GSE22139) and human normal brains (from accession series accession series GSE30563), which were obtained using Affymetrix microarrays (Human Genome U133 Plus 2.0 array, HG-U133 Plus 2; Affymetrix, Santa Clara, CA, USA), were extracted from the GEO website (http://www.ncbi. nlm.nih.gov/geo). The differentially expressed genes in MB were also determined based on comparisons with MB cell lines (Daoy and VGH-Med) and various normal brain tissues (two males aged 47 and 55 years, Cat. no. 636530; Clontech, Mountain View, CA, USA; 13 males and 10 females aged 23-86 years, Cat. no. AM7000; Ambion, Austin, TX, USA) using an Agilent Human Whole Genome Oligo 4x44K microarray system (Agilent Technologies, Santa Clara, CA, USA) according to the manufacturer's standard procedures. We deposited the Agilent microarray data onto a public domain (GSE74947). Common genes with potentially significant changes ( $>1.50$ - or $<0.67$-fold) and clear expression trends in $\mathrm{MB}$ were compared and extracted from the above-mentioned Affymetrix and Agilent microarray systems, as previously described $(17,18)$. The minimized difference in expression (GSE7578 vs. GSE30563; GSE22139 vs. GSE30563; Daoy/ VGH-Med vs. normal brains from Clontech/Ambion) between separate microarrays (standard deviation $<0.75$ ) was used to filter genes with significant differences ( $\mathrm{p}<0.05$, Student's t-test) in MB (19), and the top genes obtained were annotated based on their gene ontology (GO) (http://david.abcc.ncifcrf.gov) (20). Finally, enrichment analysis (http://compbio.charite.de) was performed to select the significant GO terms $(21,22)$.

Relative gene expression levels of synaptosomal-associated protein 25 (SNAP25) in MB cells. Total RNA from the normal brain tissue purchased from Clontech (Cat. no. 636530) was also used for gene quantification. Cellular RNA was extracted from each MB cell line using TRIzol reagent according to the manufacturer's instructions (Invitrogen, Carlsbad, CA, USA). The expression levels of total SNAP25 or its two variants (variant 1: NM_003081, and variant 2: NM_130811) in each $\mathrm{MB}$ cell line relative to those in the normal brain were determined by reverse transcription-quantitative polymerase chain reaction (RT-qPCR) in the presence of specific TaqMan probes and TaqMan Master Mix (Roche Diagnostics, Mannheim, Germany), according to the manufacturer's instructions. Briefly, amplification primer pairs for the total and variant SNAP25s (the locations are mapped in Fig. 2B) and glyceraldehyde-3-phosphate dehydrogenase (GAPDH: NM_002046), which was employed as an internal control, were designed using the Roche website (http://www.roche-applied-science. com) (Table II). LightCycler (version 4.05; Roche Diagnostics) was used to analyze the PCR kinetics. Each run also included an appropriate and predetermined diluted human reference cDNA (Clontech) as a positive control.

Protein levels of SNAP25 in MB cells. The protein levels of SNAP25 in MB cells were immunodetected by standard western blot analysis. In addition, 6 protein extracts of normal medulla oblongata (female aged 82 years, Cat. no. P1234057 from BioChain, San Leandro, CA, USA; Cat. no. ab29859 from Abcam, Cambridge, UK), normal cerebellum (male aged 66 years, cat. no. P1234040; and female aged 70 years, Cat. no. P1234041; both from BioChain), and normal brain (Cat. no. ab29466 from Abcam; female aged 38 years, Cat. no. 1303 from ProSci, Poway, CA, USA) were used in western blot analysis. Briefly, $10 \mu \mathrm{g}$ of each protein extract was diluted with reducing NuPAGE sodium dodecyl sulfate (SDS) sample buffer (Invitrogen) and heated for $10 \mathrm{~min}$ at $95^{\circ} \mathrm{C}$. The heat-denatured extracts were then electrophoresed by $12 \%$ SDS-polyacrylamide gel electrophoresis and transferred electrophoretically onto a polyvinylidene fluoride membrane (Millipore, Billerica, MA, USA) using an electroblot system (Hofer TE70 Semi-Dry Transfer Unit; GE Healthcare, Fairfield, CT, USA) with a constant current of $0.8 \mathrm{~mA} / \mathrm{cm}^{2}$. The membrane was then blocked with 5\% (w/v) skim milk in TBS-T $(50 \mathrm{mmol} / \mathrm{l}$ Tris-HCl, $\mathrm{pH} 7.5 ; 150 \mathrm{mmol} / \mathrm{l} \mathrm{NaCl}$; $0.1 \%$ Tween-20) and probed with anti-SNAP25 $\operatorname{IgG}(1: 1,000$ in blocking solution; Cat. no. HPA001830; Sigma, St. Louis, MO, USA), according to a standard procedure. This antibody cannot distinguish between different variants as its antigenic 
Table I. Characteristics of patients with medulloblastoma.

\begin{tabular}{|c|c|c|c|c|c|}
\hline $\begin{array}{l}\text { Patient } \\
\text { no. }\end{array}$ & $\begin{array}{l}\text { Gender/onset } \\
\text { age (years) }\end{array}$ & Symptom & $\begin{array}{l}\text { Image } \\
\text { analysis }\end{array}$ & Pathology & Outcome \\
\hline p't 19 & $\mathrm{~F} / 8$ & Dizziness only & $2^{*} 2^{*} 2$ tumor $\left(\mathrm{cm}^{3}\right)$ & MB, desmoplastic & $\begin{array}{l}\text { Deceased, due to } \\
\text { meta in } 2003\end{array}$ \\
\hline p't 31 & $\mathrm{M} / 6$ & $\begin{array}{l}\text { HA, vomiting, neck } \\
\text { tilting, dysmetria }\end{array}$ & R't CT, H(-) & $\mathrm{MB}$, hemispheric & $\begin{array}{l}\text { Still alive } \\
\text { in Aug, } 2009\end{array}$ \\
\hline p't 69 & $\mathrm{M} / 9$ & $\begin{array}{l}\text { Vomiting, HA for } 1 \text { week, } \\
\text { nystagmus }(+) \text {, } \\
\text { papilledema(-) }\end{array}$ & $\mathrm{CT}, \mathrm{H}$ & $\mathrm{MB}$ & $\begin{array}{l}\text { Still alive } \\
\text { in Feb, } 2009\end{array}$ \\
\hline p't 83 & $\mathrm{M} / 46$ & $\begin{array}{l}\text { Dizziness, HA, ataxia } \\
\text { for over } 20 \text { days, } \\
\text { slurred speech }\end{array}$ & L't HT, CHH & MB & $\begin{array}{l}\text { Still alive } \\
\text { in Feb, } 2009\end{array}$ \\
\hline
\end{tabular}

HA, headache; MB, medulloblastoma; $\mathrm{CHH}$, cerebellar hemisphere hydrocephalus; H, hydrocephalus; CT, cerebellar tumor; HT, hypodense tumor; meta, metastasis.

Table II. Primers and probes for used for RT-qPCR.

Gene name

(variant)

Primer sequence

Accession no.

Universal probe no.

\begin{tabular}{|c|c|c|c|}
\hline $\begin{array}{l}\text { SNAP25 } \\
\text { (Total) }\end{array}$ & $\begin{array}{l}\text { F: ATCGGGAACCTCCGTCAC } \\
\text { R: AATTCTGGTTTTGTTGGAATCAG }\end{array}$ & $\begin{array}{l}\text { NM_003081 } \\
\text { NM_130811 }\end{array}$ & \#81 \\
\hline $\begin{array}{l}\text { SNAP25 } \\
\text { (variant 1) }\end{array}$ & $\begin{array}{l}\text { F: GGCATGAACCATATCAACCA } \\
\text { R: TTTTGTAAGCATCACTTGATTTAAGC }\end{array}$ & NM_003081 & \#75 \\
\hline $\begin{array}{l}\text { SNAP25 } \\
\text { (variant 2) }\end{array}$ & $\begin{array}{l}\text { F: CTTTGTGTGTGTCCCTGTAACAA } \\
\text { R: GTTCGTCCACTACACGAGCA }\end{array}$ & NM_130811 & $\# 20$ \\
\hline GAPDH & $\begin{array}{l}\text { F: CTCTGCTCCTCCTGTTCGAC } \\
\text { R: ACGACCAAATCCGTTGACTC }\end{array}$ & NM_002046 & $\# 60$ \\
\hline
\end{tabular}

All primers and probes were designed using the Roche website (http://www.roche-applied-science.com). F, forward; R, reverse; SNAP25, synaptosomal-associated protein 25; GAPDH, glyceraldehyde-3-phosphate dehydrogenase.

peptide is located within a conserved region. The blot was then incubated with horseradish peroxidase (HRP)-conjugated anti-rabbit IgG (1:5,000 in TBS-T; Cat. no. ab6721; Abcam) and developed using the enhanced chemiluminescence method (ECL system; GE Healthcare). The GAPDH protein level in each sample was also immunodetected as an internal control using anti-GAPDH IgG (1:5,000 in TBS-T; Cat. no. AM4300; Ambion) and HRP-conjugated anti-mouse IgG (1:5,000 in TBS-T; Cat. no. ab6789; Abcam). Images of the blots were acquired using the FluorChem FC2 system (Alpha Innotech, San Leandro, CA, USA).

Immunohistochemical analysis of tissue arrays and clinical tissues. A routine immunohistochemical procedure was applied after hybridizing individual tissue sections. Immunohistochemical staining was performed using the biotin-streptavidin-peroxidase method with a VECTASTAIN ${ }^{\circledR}$
Elite ABC kit (Vector Laboratories, Burlingame, CA, USA). During epitope retrieval, the slides with tissue sections were immersed in Tris-EDTA buffer $(10 \mathrm{mM}$ Tris base, $1 \mathrm{mM}$ EDTA solution, $0.05 \%$ Tween-20, $\mathrm{pH}$ 9.0) and incubated for $20 \mathrm{~min}$ on a hot plate $\left(95-99^{\circ} \mathrm{C}\right)$, or boiled, before cooling to room temperature for $20 \mathrm{~min}$. The tissues on the slides were blocked with blocking solution (VECTASTAIN ${ }^{\circledR}$ Elite ABC kit) for $2 \mathrm{~h}$ at room temperature and probed with anti-SNAP25 (1:1,000 in blocking solution; Cat. no. HPA001830; Sigma) antibody overnight at $4^{\circ} \mathrm{C}$. The hybridized tissue sections were then washed 3 times with phosphate-buffered saline and endogenous peroxidase production was blocked with $0.3 \%$ hydrogen peroxide in distilled water for $15 \mathrm{~min}$. The specific signals in the tissue arrays were acquired by incubation with the biotin-labeled secondary antibody (VECTASTAIN ${ }^{\circledR}$ Elite $\mathrm{ABC}$ kit) for $1 \mathrm{~h}$ and developed using a peroxidase substrate solution until the development of the desired stain intensity. 
Before dehydration and mounting, hematoxylin was used as an appropriate counterstain. In addition, the tumor regions of individual tissue sections were identified by routine hematoxylin and eosin (H\&E) staining, which was performed at the Department of Pathology, Sijhih Cathay General Hospital, New Taipei, Taiwan. Finally, independent pathologists diagnosed the imaging results.

Generation of stable SNAP25-overexpressing MB cells and morphological changes of cells with SNAP25 expression by immunofluorescence. A human cDNA that coded for a protein related to SNAP25 was amplified by qualitative PCR from a Human Reference cDNA (Clontech) using an appropriate primer pair (forward, CTCGAGATGGCCGAAGACGCAGACAT; reverse, GGATCCACCACTTCCCAGCATCTTTG). PCR bands with the predicted size were isolated routinely and sequenced (ABI 3100) using an ABI Prism Big Dye Terminator Cycle Sequencing Ready reaction kit (both from Applied Biosystems, Framingham, MA, USA) to confirm the gene identities. The green fluorescent protein (GFP)-containing vector, pEGFP C3, was used as the expression vector (Invitrogen). Both pEGFP C3 and pEGFP C3-SNAP25 (the SNAP25-containing pEGFP C3) were isolated with a Genopure Plasmid Midi Maxi kit (Roche Diagnostics). In total, $7 \times 10^{4} \mathrm{MB}$ cells (Daoy) were seeded into each well of a 6-well plate. On the second day, cells at $80-90 \%$ confluence were transfected with the purified plasmid using FuGENE ${ }^{\circledR}$ HD (Roche Diagnostics) according to the following procedures: $2 \mu \mathrm{g}$ of plasmid DNA (in $10 \mu \mathrm{l}$ $\mathrm{ddH}_{2} \mathrm{O}$ ) was mixed with $100 \mu \mathrm{l}$ of serum-free medium; the transfection reagent, $7 \mu \mathrm{l} \mathrm{FuGENE}{ }^{\circledR} \mathrm{HD}$, was then added to the $100 \mu \mathrm{l}$ serum-free medium and incubated for $20 \mathrm{~min}$ at room temperature. The resulting complex mixture was subsequently added to the cells. The transfected cells were placed into selection medium containing $500 \mu \mathrm{g} / \mathrm{ml} \mathrm{G} 418$ (also known as Geneticin $^{\mathrm{TM}}$; BioShop, Oakville, ON, Canada) the following day. Next, increasing concentrations of G418 (up to $1,000 \mu \mathrm{g} / \mathrm{ml}$ ) were used to select stable SNAP25-overexpressing clones over the next 30 days. The increasing SNAP25 mRNA levels in the stable clones were quantified by RT-qPCR and protein was immunoblotted by western blot analysis, as described above. The GFP was also immunodetected with anti-EGFP IgG (1:1,000 in blocking solution; Cat. no. ab184601; Abcam). Normal neural cells were acquired by a differentiation of placenta-derived multipotent cells (PDMCs) under a 3-day incubation with 0.4 mM 3-isobutyl-1-methylxanthine (IBMX) (23). The expression pattern of SNAP25 (green) was immunostained with rabbit anti-SNAP25 antibody (1:100; ab109105; Abcam) and DyLight 488-conjugated goat anti-rabbit IgG antibody (1:200; A120101D2; Bethyl Laboratories, Montgomery, TX, USA). The glial fibrillary acidic protein (GFAP), the Tau protein, and pan neuronal markers (PNM) were respectively probed using antiGFAP (1:200; MAB3402; Millipore), anti-Tau (1:100, ab80579; Abcam) and anti-PNM antibodies (1:25; MAB2300, Millipore). Finally, the Cy3-conjugated goat anti-mouse antibody (1:200; AP124C; Millipore) was used as the secondary antibody. For the immunofluorescence analysis, 4',6-diamidino-2-phenylindole (DAPI) was used to counterstain the nucleus and exhibited blue color. The fluorescent samples were then dehydrated, mounted, and analyzed using a Nikon Eclipse 80i fluorescence microscope (Nikon Instruments, Melville, NY, USA).

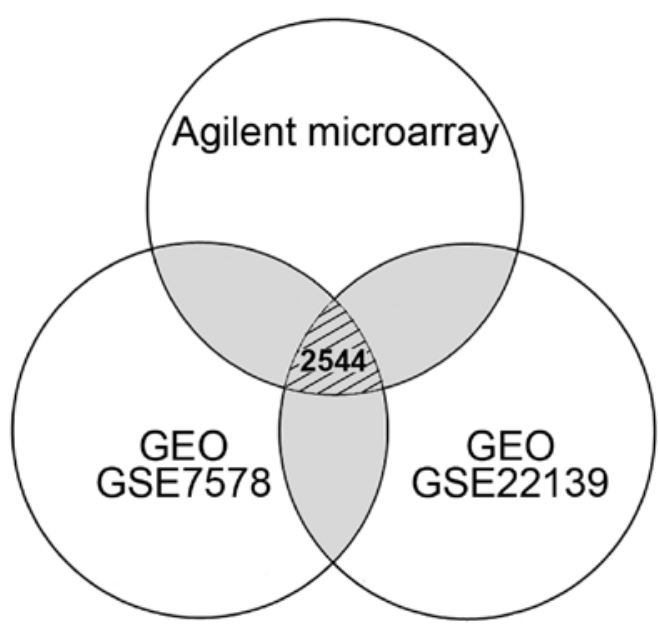

Figure 1. Venn diagram indicating the number of differentially expressed genes in medulloblastoma from the comparisons of different microarray systems. A total of 4,596 (1,656 up- and 2,940 downregulated) genes from Agilent microarray system, 12,262 (8,306 up- and 3,956 downregulated) genes from GEO GSE7578, and 14,257 (11,274 up- and 2,983 downregulated) genes from GEO GSE22139 were respectively selected according to their differential expression. Gray regions indicated the genes repeated in different experiments. Only 2,544 genes with consistent expression level differences were determined by comparing the data obtained from Agilent and Affymetrix (GEO GSE7578 and GSE22139) microarrays. GEO, Gene Expression Omnibus; GSE, GEO series.

Determination of the cytotoxicity of arabinofuranosyl cytidine (Ara-C) in SNAP25-expressing MB cells. MB cells (Daoy) without or with SNAP25 overexpression were cultured at $3 \times 10^{3}$ cells/well in 96-well plates for $24 \mathrm{~h}$. Cell viability was examined using a Cell Counting kit-8 (CCK-8; Sigma) in the presence of various concentrations (from $0.1 \mathrm{nM}$ to $10 \mathrm{mM}$ ) of Ara-C (C1768; Sigma) following incubation for $48 \mathrm{~h}$, according to the manufacturer's instructions. Briefly, the absorbance of each well was read at $450 \mathrm{~nm}$ using a microplate reader (iMark; Bio-Rad, Richmond, CA, USA) after 2-4 h of incubation until a brown precipitate formed.

Statistical analysis. The differences in SNAP25 expressions, numbers of dendrites, and Ara-C concentrations were compared using the Student's t-test. Statistical analysis was performed using SPSS 13.0 (SPSS, Inc., Somers, NY, USA). The data were representative of at least 3 experiments with similar results, and a value of $\mathrm{p}<0.05$ was considered to indicate a statistically significant difference.

\section{Results}

Significant candidates with differential expression levels in $M B$. Differentially expressed genes in MB were selected using Agilent and Affymetrix microarrays (Fig. 1). We identified 4,596 candidates based on their significantly up- ( $>1.50$-fold) or downregulated ( $<0.67$-fold) expression levels in MB cells using Agilent oligonucleotide microarrays. In addition, over 10,000 genes with differential expression levels $(>1.50$ - or $<0.67$-fold) were obtained from the public database. As shown in Fig. 1, 2,544 genes with consistent expression level differences were determined by comparing the data obtained from 

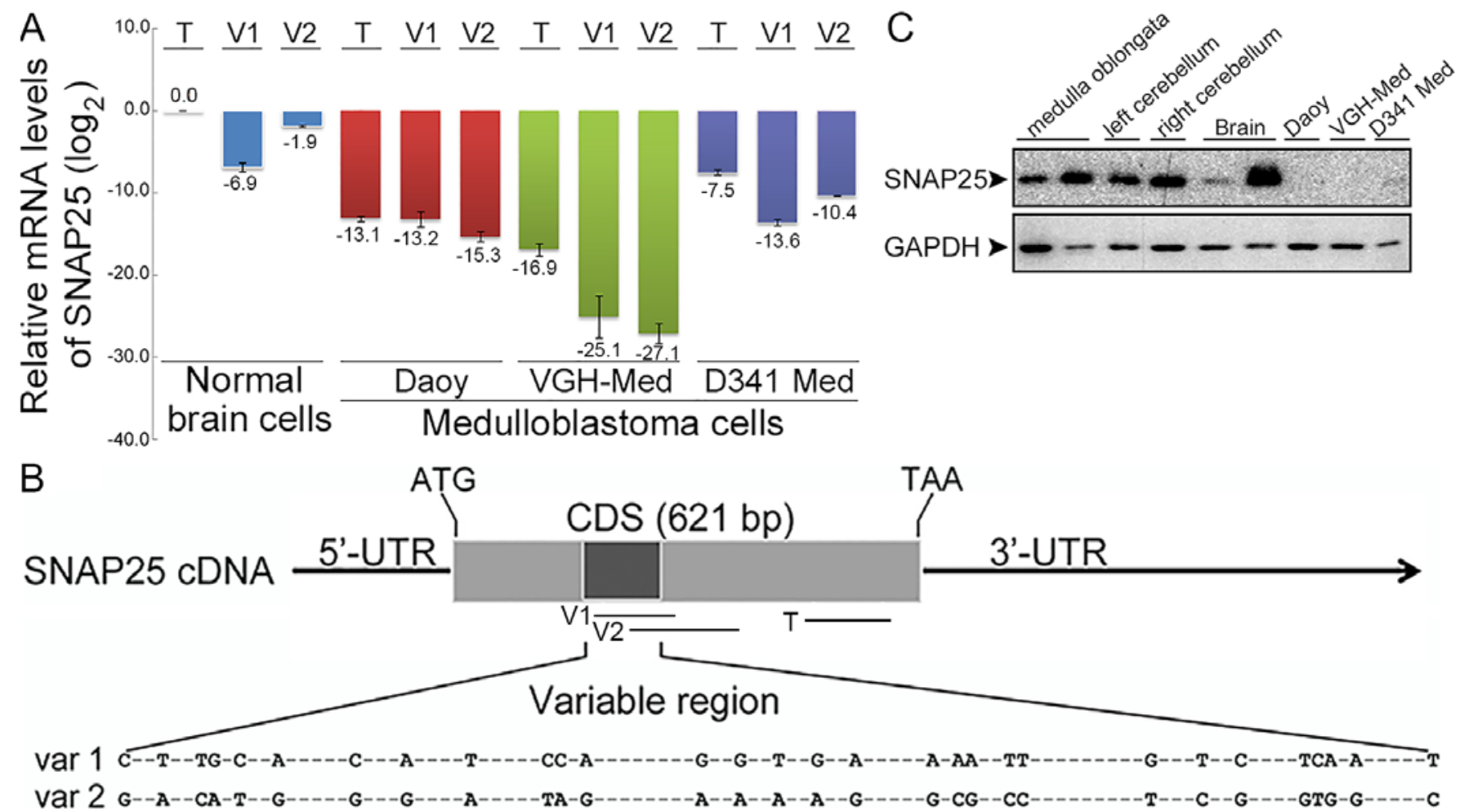

Figure 2. Expression differences of synaptosomal-associated protein 25 (SNAP25) between medulloblastoma and normal brain cells. (A) Comparative mRNA levels of total SNAP25 and variants by RT-qPCR. SNAP25 mRNA levels were quantified in three medulloblastoma (MB) cell lines (Daoy cells: sonic hedgehog subgroup; VGH-Med; D341 Med: group 3 subgroup) and normal brain cells. Each SNAP25 mRNA level in MB cell lines was normalized with their endogenous glyceraldehyde-3-phosphate dehydrogenenase (GAPDH) mRNA level and relative to normal brain cells. All data were then $\log _{2}$ transformed $\left[\log _{2}\right.$ (total SNAP25 of normal brains), 0]. (B) Map of primers for quantifications of total SNAP25 and variants. -, indicates the conserved sequences. (C) Endogenous SNAP25 protein in MB cell lines. Protein levels of SNAP25 (25 kDa) and GAPDH ( $36 \mathrm{kDa})$ were detected by western blot analysis. Lanes 1 and 2, normal medulla oblongata from BioChain and Abcam, respectively; lanes 3 and 4, left and right cerebellum from BioChain; lanes 5 and 6, normal brains from Abcam and ProSci; lanes 7 to 9 , Daoy, VGH-Med and D341 Med MB cell lines. T, V1, and V2 indicated the amplified regions. T, total SNAP25; V1 or var 1, variant 1; V2 or var 2, variant 2. CDS, coding sequence; 5'-UTR, 5'-untranslated region; 3'-UTR, 3'-untranslated region; ATG, start codon; TAA, stop codon.

different microarray systems (Affymetrix and Agilent), but only 278 genes (130 upregulated and 148 downregulated: link to download these significant genes in MB cells, https://drive. google.com/file/d/0Bw-QVez2CXs5YWhaMER1Z19Kd1k/ view?usp=sharing) exhibited similar expression patterns. From the 278 genes, 86 candidates (41 upregulated and 45 downregulated) were also identified based on consistent differences in their expression levels according to different microarrays (standard deviation $<0.75 ; \mathrm{p}<0.05$ ). We found that many genes had statistically different expression levels according to the whole-genome microarrays, where $35 \mathrm{GO}$ terms were enriched, including vesicle, neuron part and synapse. Among the candidates, SNAP25 was associated with 6 GO terms (GO0042995, cell projection; GO0044763, single-organism cellular process; GO0097458, neuron part; GO0044699, single-organism process; GO0045202, synapse; GO0016020, membrane) and its expression level was reduced in MB cells. Soluble $N$-ethylmaleimide-sensitive factor attachment protein receptors (SNAREs) and their associated proteins play critical roles in vesicle docking, priming, fusion, and the synchronization of neurotransmitter release via exocytosis pathways $(24,25)$. Briefly, the significant GO terms with functional similarity, including molecular function, biological process and cellular component (Table III), were explored based on their GO annotations and using enrichment analysis. In particular, genes for SNAREs annotated with the function 'vesicle' were identified and one of these proteins, SNAP25, had significantly lower expression levels in the MB cells in all of the microarrays. It should be noted that the probe used for SNAP25 in the Agilent microarrays was the probe A_23_P210756 near the stop codon (TAA), which indicated the total SNAP25 expression level.

Decreased protein expression levels of SNARE and SNAP25 in $M B$ cells. The differences in the mRNA and protein levels also validated the differential expression of the SNARE protein. Two SNAP25 variants have been reported previously (26). For the total SNAP25 or individual variants, lower mRNA levels were detected in each MB cell line compared with those in normal brain cells (Fig. 2A). Moreover, we detected different expression patterns for variants 1 and 2 . Normal brain cells and D341 Med (group 3 subgroup) expressed relatively more of variant 2, whereas lower levels of variant 2 were detected in Daoy cells [sonic hedgehog (SHH) subgroup] and VGH-Med cells. The very high difference in the gene expression level of total SNAP25 was also replicated in the protein levels compared with the normal brain tissues, as well as in other normal tissues in the brain stem, such as the medulla oblongata and cerebellum (Fig. 2C). The difference in SNAP25 expression was also confirmed by immunohistochemical staining analyses of our archived MB sections, where the MB lesions identified 
Table III. The significant gene ontology terms with similarity.

\begin{tabular}{|c|c|c|}
\hline GO no. & GO name & p-value \\
\hline \multicolumn{3}{|c|}{ Molecular function } \\
\hline 0016667 & Oxidoreductase activity, acting on a sulfur group of donors & $<0.005$ \\
\hline 0016853 & Isomerase activity & $<0.005$ \\
\hline $0005543^{\mathrm{a}}$ & Phospholipid binding & $<0.005$ \\
\hline \multicolumn{3}{|c|}{ Biological process } \\
\hline $0044763^{\mathrm{b}}$ & Single-organism cellular process & $<0.005$ \\
\hline $0044699^{\mathrm{b}}$ & Single-organism process & $<0.005$ \\
\hline 0032502 & Developmental process & $<0.005$ \\
\hline 0050687 & Negative regulation of defense response to virus & $<0.005$ \\
\hline 0018904 & Ether metabolic process & $<0.005$ \\
\hline 2000374 & Regulation of oxygen metabolic process & $<0.01$ \\
\hline 0002832 & Negative regulation of response to biotic stimulus & $<0.01$ \\
\hline 2000376 & Positive regulation of oxygen metabolic process & $<0.01$ \\
\hline 0032956 & Regulation of actin cytoskeleton organization & $<0.01$ \\
\hline 0060138 & Fetal process involved in parturition & $<0.01$ \\
\hline 0097212 & Lysosomal membrane organization & $<0.01$ \\
\hline 0097350 & Neutrophil clearance & $<0.01$ \\
\hline 0030155 & Regulation of cell adhesion & $<0.01$ \\
\hline 0048519 & Negative regulation of biological process & $<0.01$ \\
\hline 0048133 & Male germ-line stem cell division & $<0.01$ \\
\hline 0097213 & Regulation of lysosomal membrane permeability & $<0.01$ \\
\hline 0051611 & Regulation of serotonin uptake & $<0.01$ \\
\hline 0002698 & Negative regulation of immune effector process & $<0.01$ \\
\hline \multicolumn{3}{|c|}{ Cellular component } \\
\hline $0042995^{\mathrm{b}}$ & Cell projection & $<0.005$ \\
\hline 0098563 & Intrinsic component of synaptic vesicle membrane & $<0.005$ \\
\hline 0030285 & Integral component of synaptic vesicle membrane & $<0.005$ \\
\hline $0097458^{b}$ & Neuron part & $<0.005$ \\
\hline 0043230 & Extracellular organelle & $<0.005$ \\
\hline 0065010 & Extracellular membrane-bounded organelle & $<0.005$ \\
\hline 0031982 & Vesicle & $<0.005$ \\
\hline 0043256 & Laminin complex & $<0.005$ \\
\hline 0005856 & Cytoskeleton & $<0.005$ \\
\hline 0005788 & ER lumen & $<0.005$ \\
\hline 0005793 & ER-Golgi intermediate compartment & $<0.01$ \\
\hline $0045202^{\mathrm{b}}$ & Synapse & $<0.01$ \\
\hline 0005605 & Basal lamina & $<0.01$ \\
\hline $0016020^{\mathrm{a}, \mathrm{b}}$ & Membrane & $<0.01$ \\
\hline
\end{tabular}

ancluding SNAP91; bincluding SNAP25. GO, gene ontology; ER, endoplasmic reticulum.

by H\&E staining expressed less SNAP25 protein (Fig. 3). By contrast, SNAP25 was expressed at normal levels in the nontumor regions of the same MB tissue sections.

Increased dendrite density and chemotherapeutic effects on SNAP25-expressing MB cells. The stable clones of
Daoy cells with pEGFP C3 or pEGFP C3-SNAP25 were selected as described above. The mRNA level of SNAP25 in pEGFP C3-SNAP25-transfected Daoy cells was extremely higher $(>1,0000$ fold) than in cells transfected with only pEGFP C3 (Fig. 4A). This overexpressed SNAP25 was also specifically immunodetected, wheras only GFP could be 

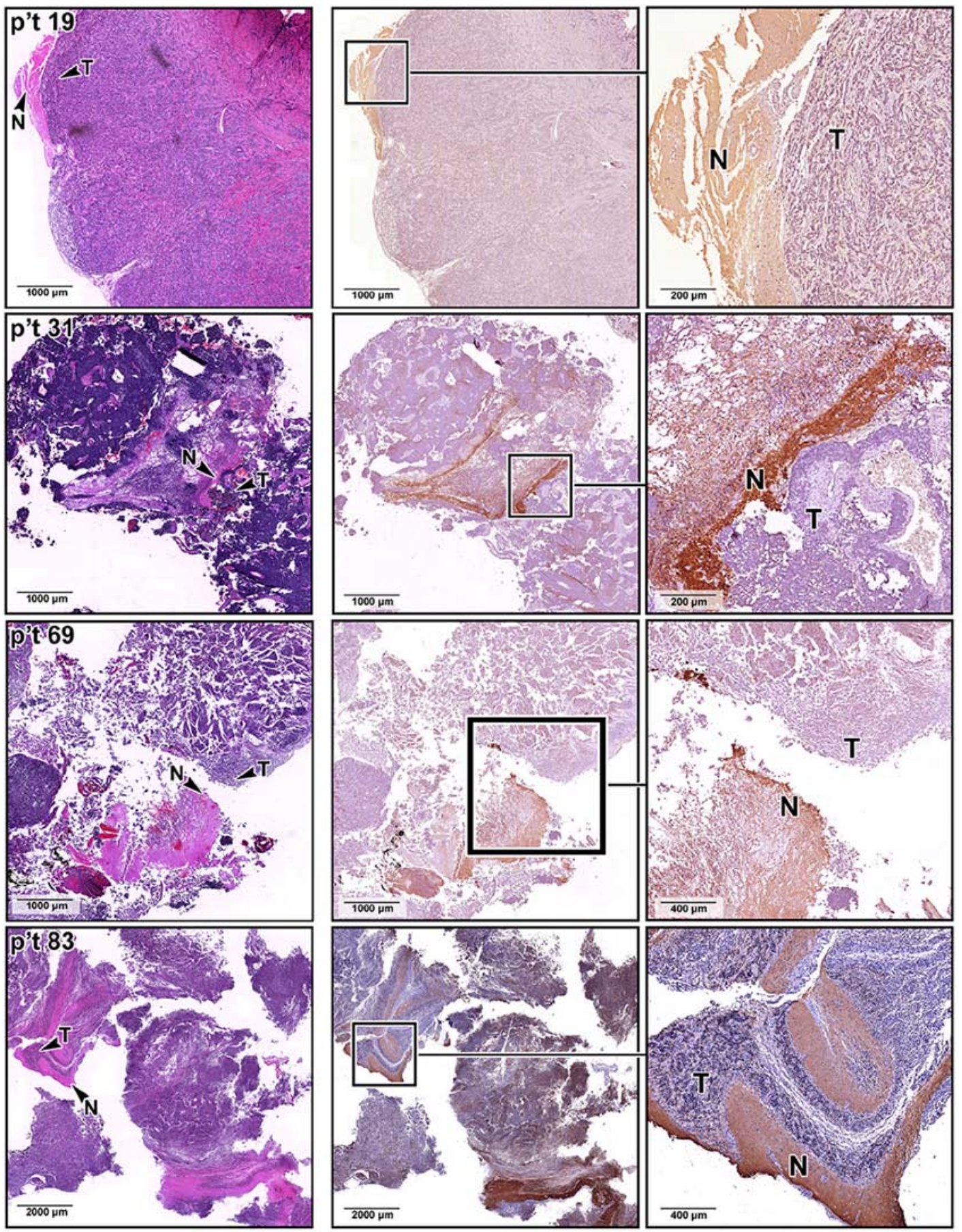

Figure 3. Distinct protein levels of synaptosomal-associated protein 25 (SNAP25) in normal and medulloblastoma tissues of patients. Archived medulloblastoma (MB) tissues were acquired and MB lesions were identified by hematoxylin and eosin (H\&E) staining (left panel). The parts of normal (N) and tumor (T) tissues were indicated and identified by the pathologists at the Department of Pathology, Sijhih Cathay General Hospital. Immunostainings of SNAP25 protein (middle panel) and the magnified views (right panel) showed the low expression in MB lesions and the high expression in normal regions. Scale bars were indicated at the lower left corner of the images.

hybridized in the cells with pEGFP C3 (Fig. 4B). A morphological change in the MB cells was associated with SNAP25 expression. Daoy cells and VGH-Med cells with only GFP, but low endogenous SNAP25 expression, had a smooth cell membrane (Fig. 5). None of the cells which only expressed GFP exhibited significant dendrites. By contrast, many dendrites were observed on the membrane of each cell that overexpressed GFP/SNAP25 fusion protein (the lower panels of Fig. 5A and B). This was also supported by the neural differen- tiation analysis, which showed that markedly positive levels of SNAP25 were detected in differentiated neural cells (Fig. 5C). Currently, Ara-C is being developed as a chemical agent for the clinical treatment of MB $(27,28)$. We found that the protein expression of SNAP25 in Daoy cells increased susceptibility to Ara-C. The half-maximal inhibitory concentration of Ara-C was significantly lower for the SNAP25-expressing Daoy cells $(96.8 \pm 29.5 \mathrm{nM})$ compared with that in cells that had low endogenous SNAP25 levels $(171.6 \pm 34.0 \mathrm{nM})(\mathrm{p}<0.05)$ (Fig. 6). 
A

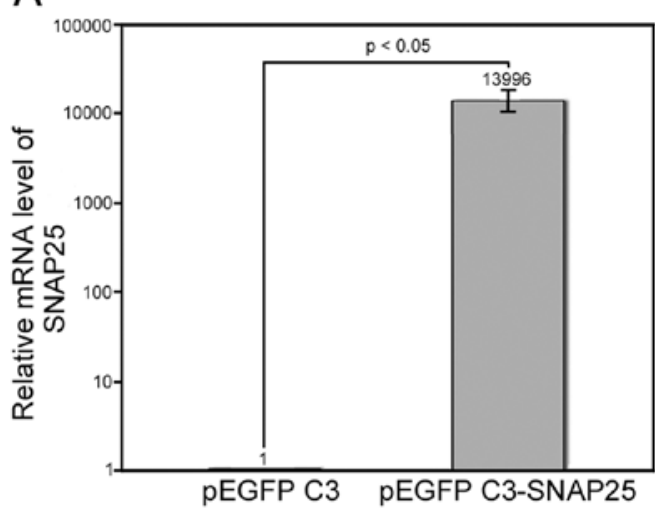

B

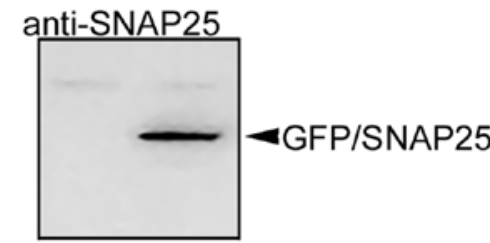

anti-GFP
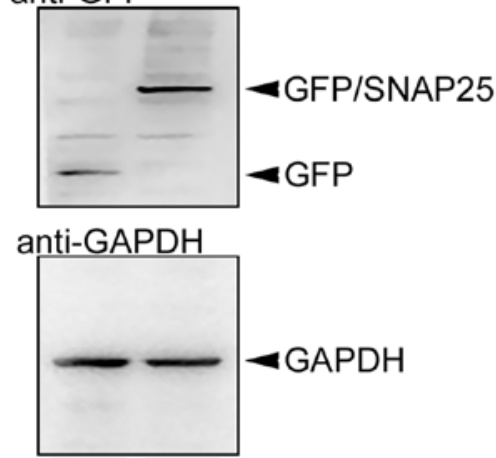

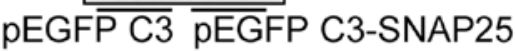

Figure 4. Validation of overexpressed synaptosomal-associated protein 25 (SNAP25) in Daoy cells. (A) High mRNA level of SNAP25 in cells transfected with pEGFP C3-SNAP25. The increasing SNAP25 mRNA levels in the stable clones were quantified by RT-qPCR. The difference in mRNA levels was compared using the Student's t-test. Data are representative of at least 3 experiments with similar results, and a value of $p<0.05$ was considered to indicate significance. (B) Expression of SNAP25 protein in cells transfecdted with pEGFP C3-SNAP25. The increasing SNAP25 protein expression was immunoblotted by western blot analysis. GFP, green fluorescent protein; GAPDH, glyceraldehyde-3-phosphate dehydrogenase.

\section{A Daoy}

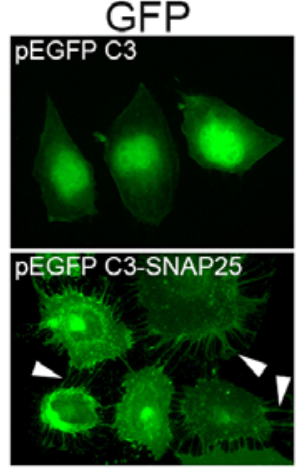

\section{B VGH-Med}

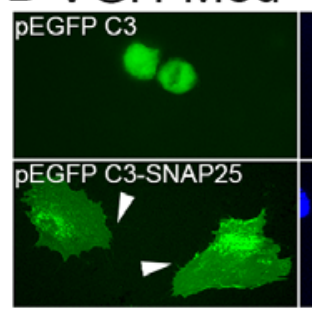

DAPI
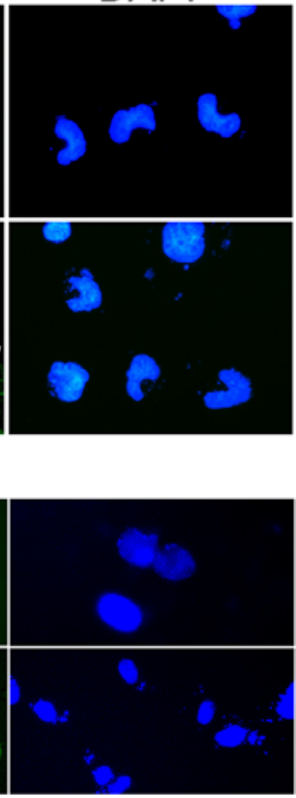

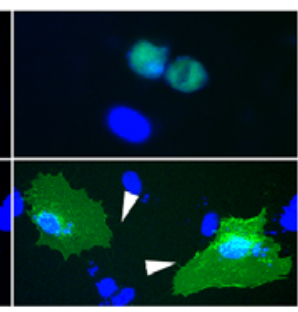

C PDMC-derived neural cells

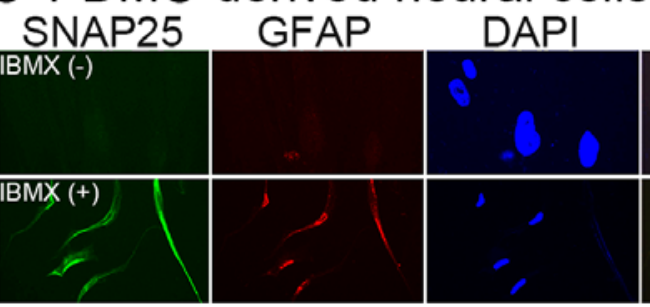

SNAP25

$\mathbb{B}$
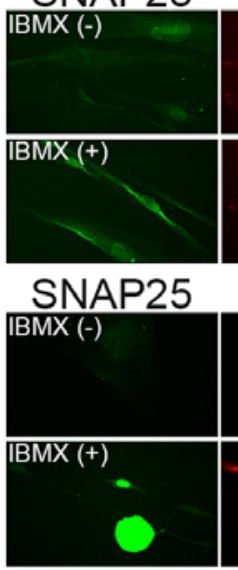

TAU

DAPI

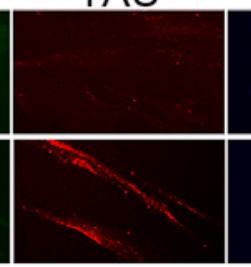

PNM

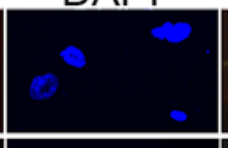

merge

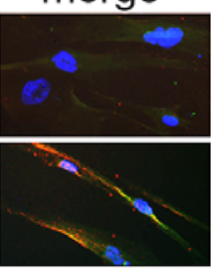

DAPI

merge
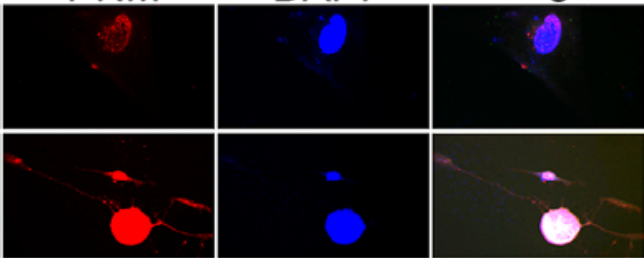

Figure 5. Morphological changes of cells with synaptosomal-associated protein 25 (SNAP25) expression. (A) The dendrites of Daoy cells with SNAP25 expression. (B) The dendrites of VGH-Med cells with SNAP25 expression. The cells transfected with pEGFP C3 vector emitted a green fluorescence throughout the cell and the SNAP25-overexpressing cells (pEGFP C3-SNAP25) formed dendrites that emitted green fluorescence. DAPI (blue) indicated the nucleus. (C) SNAP25 expression in normal neural cells. White arrowheads indicate the dendrites. GFP, green fluorescent protein; GFAP, glial fibrillary acidic protein; TAU, Tau protein; PNM, pan neuronal marker; DAPI, 4',6-diamidino-2-phenylindole; IBMX, 3-isobutyl-1-methylxanthine.

\section{Discussion}

Cancer, including MB, is generally attributed to genetic aberrations in tumor tissues $(29,30)$. Previous studies have explored the genetic alterations in MB to determine their associations with the clinical prognosis, thereby facilitating the development of therapeutic approaches based on analyses of high-throughput databases (29,31). Moreover, internet-based tools have been 


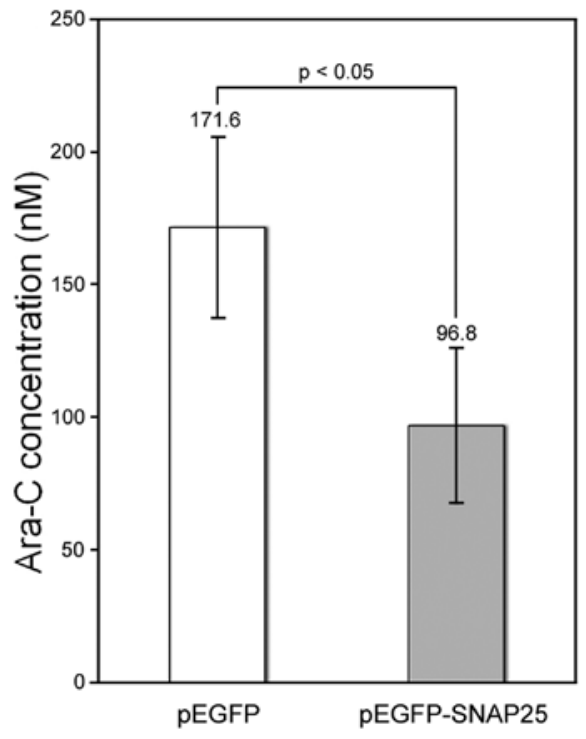

Figure 6. Change of susceptibility to arabinofuranosyl cytidine (Ara-C) for SNAP25-expressing Daoy cells. The half-maximal inhibitory concentration of Ara-C was determined under a dose-dependent manner (from 0.1 to $10 \mathrm{mM}$ ) of Ara-C following incubation for $48 \mathrm{~h}$. The surviving cells were counted by CCK-8 assay. Data are the means \pm SD of triplicate independent experiments Ara-C, arabinofuranosyl cytidine; CCK-8, cell counting kit- 8 . SD, standard derivation.

used to determine the effectiveness of treatments for childhood MB (32). In the present study, we performed comparative genome-wide surveys to determine the molecular characteristics of MB and to identify potential targets for MB treatment.

The synaptic vesicle membrane glycoprotein, synaptophysin, has been studied in the context of MB (30). Over the past decade, the subcellular localizations of SNAREs and their ability to form the so-called SNARE complex have been shown to play important roles in the minimal fusion machinery and in cell-to-cell signaling $(33,34)$. In addition, SNAREs may also be involved in the functional regulation of some ion channels (35). Ramakrishnan et al suggested that deficits in the expression of SNAREs may impair the functions of the brain and sense organs (25). A deficiency of SNAP25 may block normal vesicle fusion in brain cells $(36,37)$. SNAP25 is known to be involved in endocytosis or exocytosis during vesicle mobilization, where its role is facilitated by other SNAREs and syntaxins $(34,38,39)$. Furthermore, SNAP25 may interact with various proteins that drive the spontaneous calcium-independent fusion of synaptic vesicles (40). In addition to SNAP25, another SNARE protein, synaptic vesicle protein synaptophysin, has been shown to have differential expression levels in MB (41). This suggests that a complex mechanism affects the production of synaptic vesicles during MB tumorigenesis and that SNAREs are critical for normal vesicle fusion (42).

Similarly, reduced levels of SNAP25 have also been detected in the hippocampus of patients with schizophrenia $(43,44)$. Moreover, Dubuc et al reported that the WNT subgroup expressed higher levels of variant 2 (26). Similarly, high levels of variant 2 were detected in normal brain cells and in D341 Med cells (group 3 subgroup). By contrast, lower levels were expressed in Daoy cells (SHH subgroup) and VGH-Med cells. This implies that the expression patterns of SNAP25 variants may be subgroup specific. Recent efforts at stratifying
MBs based on their molecular features have revolutionized our understanding of this morbidity (9). We believe that the knowledge of classification may contribute to the development of novel molecular therapies targeting a specific subgroup of MBs (45).

A number of clinical studies have shown that SNAP25 participates in synaptic plasticity and it may be associated with a separate synaptic pathology $(43,46)$. These hypotheses were also supported by our cytological results, where an increased dendrite density was observed in Daoy cells and VGH-Med cells when the expression of SNAP25 was restored in the present study. Thus, nerve impulses may be conducted via these dendrites (47). The molecular significance of SNAP25 in brain cells may be related to protein-protein interactions with many other proteins, such as syntaxin 1A and syntaxinbinding protein $1(38,48,49)$. Moreover, dendrite instability has been detected in many neuronal diseases (50). The decreased dendrite density associated with reduced levels of SNAP25 and the presence of MB cells without dendrites may be related to MB tumorigenesis. Therefore, the SNARE complex, which includes SNAP25, may play various complex roles when synaptic vesicle fusion occurs after a nerve impulse reaches the synapse. However, the SNAP25-restored dendrites may be more important in the $\mathrm{SHH}$ subgroup of MB. Other than the SHH subgroup, three principle subgroups (WNT, Group 3 and 4) were also defined by their distinct molecules $(51,52)$. In the present study, only the Daoy cells (SHH subgroup) (53) and an undefined MB subgroup, VGH-Med cells, could restore dendrites in the presence of SNAP25. These implied that the restoration of dendrites caused by SNAP25 expression may lead cells to the terminal differentiation and then loss of tumorigenicity (54). By contrast, the D341 Med cells classified in the Group 3 subgroup (55) did not produce similar results (data not shown). Therefore, we hypothesized that SNAP25 may play a critically significant role in $\mathrm{MB}$, particularly for the $\mathrm{SHH}$ subgroup, where Daoy cells and VGH-Med cells exhibited similar molecular patterns.

Alterations in synaptic vesicle fusion or dendrite density may be associated with MB chemotherapy. In 1998, Hodel reported that a reduction of SNAP25 in the brain impaired neuronal dopamine signaling, thereby providing a target for the development of therapeutic treatments (56). An important morphogen for neural differentiation, retinoic acid, can enhance MB chemosensitivity (57). These data indicate that optimal synaptic vesicle fusion and a normal dendrite density may improve the chemotherapeutic outcomes in this specific neuronal disorder. The results of our analysis of Ara-C treatment in MB cells also support this hypothesis. Thus, restoring the expression of SNAP25 in MB cells can increase the sensitivity to Ara-C, which is an intrathecal chemotherapeutic that is used as an antineoplastic agent in children (58).

Genomic variation affects the structure and expression of genes; thus, genetic analyses may enhance our understanding of the predisposition, biology and clinical response to therapy in various diseases (59). Methods are needed that highlight biomarkers with potential clinical utility in the diagnosis and treatment of the common types of primary pediatric brain tumors (15). In the present study, SNAP25 was less abundant in the tissue arrays and in our enrolled patients. Thus, we suggest that the reduced levels of SNAP25 may have implications for 
clinical treatment. In addition, the dendrite density was restored when MB cells expressed SNAP25 protein, which may rebuild the synaptic junctions between neuronal cells. The pyrimidine analogue, Ara-C, has been reported to be one of the most effective agents in inducing the apoptosis of many tumor cells (60). However, the chemosensitivity to Ara-C was greatly increased when MB cells expressed SNAP25.

In conclusion, our results suggest that a SNARE complex that includes SNAP25 is crucial for the dendrite formation and is associated with the effects of targeted chemotherapy. A downregulation of SNAP25 may impede targeted chemotherapy as the SNAREs in brain cells may not form correctly. The detection of SNAP25 expression in MB cells may be essential for the chemotherapeutic application of Ara-C.

\section{Acknowledgements}

This study was supported by grants from the Cathay General Hospital and Taipei Medical University (no. 103CGH-TMU-02) and the Cathay General Hospital (no. CGH-MR-10122).

\section{References}

1. Shih DJ, Northcott PA, Remke M, Korshunov A, Ramaswamy V, Kool M, Luu B, Yao Y, Wang X, Dubuc AM, et al: Cytogenetic prognostication within medulloblastoma subgroups. J Clin Oncol 32: 886-896, 2014.

2. Anne SL, Govek EE, Ayrault O, Kim JH, Zhu X, Murphy DA, Van Aelst L, Roussel MF and Hatten ME: WNT3 inhibits cerebellar granule neuron progenitor proliferation and medulloblastoma formation via MAPK activation. PLoS One 8: e81769, 2013.

3. Lastowska M, Al-Afghani H, Al-Balool HH, Sheth H, Mercer E, Coxhead JM, Redfern CP, Peters H, Burt AD, Santibanez-Koref M, et al: Identification of a neuronal transcription factor network involved in medulloblastoma development. Acta Neuropathol Commun 1: 35, 2013.

4. Rajurkar M, Huang H, Cotton JL, Brooks JK, Sicklick J, McMahon AP and Mao J: Distinct cellular origin and genetic requirement of Hedgehog-Gli in postnatal rhabdomyosarcoma genesis. Oncogene 33: 5370-5378, 2014.

5. Unland R, Kerl K, Schlosser S, Farwick N, Plagemann T, Lechtape B, Clifford SC, Kreth JH, Gerss J, Mühlisch J, et al: Epigenetic repression of the dopamine receptor D4 in pediatric tumors of the central nervous system. J Neurooncol 116: 237-249, 2014.

6. MacDonald TJ, Aguilera D and Castellino RC: The rationale for targeted therapies in medulloblastoma. Neuro Oncol 16: 9-20, 2014.

7. Robinson G, Parker M, Kranenburg TA, Lu C, Chen X, Ding L, Phoenix TN, Hedlund E, Wei L, Zhu X, et al: Novel mutations target distinct subgroups of medulloblastoma. Nature 488: 43-48, 2012.

8. Gerber NU, Mynarek M, von Hoff K, Friedrich C, Resch A and Rutkowski S: Recent developments and current concepts in medulloblastoma. Cancer Treat Rev 40: 356-365, 2014.

9. Jahn R and Fasshauer D: Molecular machines governing exocytosis of synaptic vesicles. Nature 490: 201-207, 2012.

10. Ma HI, Kao CL, Lee YY, Chiou GY, Tai LK, Lu KH, Huang CS, Chen YW, Chiou SH, Cheng IC, et al: Differential expression profiling between atypical teratoid/rhabdoid and medulloblastoma tumor in vitro and in vivo using microarray analysis. Childs Nerv Syst 26: 293-303, 2010.

11. Wybranska I, Polus A, Mikolajczyk M, Knapp A, Sliwa A, Zapala B, Staszel T and Dembinska-Kiec A: Apoptosis-related gene expression in glioblastoma (LN-18) and medulloblastoma (Daoy) cell lines. Hum Cell 26: 137-148, 2013.

12. Fiaschetti G, Castelletti D, Zoller S, Schramm A, Schroeder C, Nagaishi M, Stearns D, Mittelbronn M, Eggert A, Westermann F, et al: Bone morphogenetic protein-7 is a MYC target with prosurvival functions in childhood medulloblastoma. Oncogene 30: 2823-2835, 2011.
13. Wiederschain D, Chen L, Johnson B, Bettano K, Jackson D, Taraszka J, Wang YK, Jones MD, Morrissey M, Deeds J, et al: Contribution of polycomb homologues Bmi-1 and Mel-18 to medulloblastoma pathogenesis. Mol Cell Biol 27: 4968-4979, 2007.

14. Kong B, Yang T, Chen L, Kuang YQ, Gu JW, Xia X, Cheng L and Zhang JH: Protein-protein interaction network analysis and gene set enrichment analysis in epilepsy patients with brain cancer. J Clin Neurosci 21: 316-319, 2014.

15. Russell MD, Young AM and Karri SK: Biomarkers of pediatric brain tumors. Front Pediatr 1: 7, 2013.

16. Rustici G, Kolesnikov N, Brandizi M, Burdett T, Dylag M, Emam I, Farne A, Hastings E, Ison J, Keays M, et al: ArrayExpress update - trends in database growth and links to data analysis tools. Nucleic Acids Res 41: D987-D990, 2013.

17. Glatt SJ, Everall IP, Kremen WS, Corbeil J, Sásik R, Khanlou N, Han M, Liew CC and Tsuang MT: Comparative gene expression analysis of blood and brain provides concurrent validation of SELENBP1 up-regulation in schizophrenia. Proc Natl Acad Sci USA 102: 15533-15538, 2005.

18. Tarnopolsky M, Phillips S, Parise G, Varbanov A, Demuth J, Stevens P, Qu A, Wang F and Isfort R: Gene expression, fiber type, and strength are similar between left and right legs in older adults. J Gerontol A Biol Sci Med Sci 62: 1088-1095, 2007.

19. Adler P, Kolde R, Kull M, Tkachenko A, Peterson H, Reimand J and Vilo J: Mining for coexpression across hundreds of datasets using novel rank aggregation and visualization methods. Genome Biol 10: R139, 2009.

20. Alvo M, Liu Z, Williams A and Yauk C: Testing for mean and correlation changes in microarray experiments: An application for pathway analysis. BMC Bioinformatics 11: 60, 2010.

21. Subramanian A, Tamayo P, Mootha VK, Mukherjee S, Ebert BL, Gillette MA, Paulovich A, Pomeroy SL, Golub TR, Lander ES, et al: Gene set enrichment analysis: A knowledge-based approach for interpreting genome-wide expression profiles. Proc Natl Acad Sci USA 102: 15545-15550, 2005.

22. Bauer S, Grossmann S, Vingron $M$ and Robinson PN: Ontologizer 2.0 - a multifunctional tool for GO term enrichment analysis and data exploration. Bioinformatics 24: 1650-1651, 2008.

23. Yen BL, Chien CC, Chen YC, Chen JT, Huang JS, Lee FK and Huang HI: Placenta-derived multipotent cells differentiate into neuronal and glial cells in vitro. Tissue Eng Part A 14: 9-17, 2008.

24. Northcott PA, Dubuc AM, Pfister S and Taylor MD: Molecular subgroups of medulloblastoma. Expert Rev Neurother 12: 871-884, 2012.

25. Ramakrishnan NA, Drescher MJ and Drescher DG: The SNARE complex in neuronal and sensory cells. Mol Cell Neurosci 50: 58-69, 2012.

26. Dubuc AM, Morrissy AS, Kloosterhof NK, Northcott PA, Yu EP, Shih D, Peacock J, Grajkowska W, van Meter T, Eberhart CG, et al: Subgroup-specific alternative splicing in medulloblastoma. Acta Neuropathol 123: 485-499, 2012.

27. Cefalo MG, De Ioris MA, Cacchione A, Longo D, Staccioli S, Arcioni F, Bernardi B and Mastronuzzi A: Wernicke encephalopathy in pediatric neuro-oncology: Presentation of 2 cases and review of literature. J Child Neurol 29: NP181-NP185, 2014.

28. Nygaard R and Kivivuori SM: Treatment for recurrent medulloblastoma with intrathecal liposomal cytarabine and systemic metronomic combination therapy. Anticancer Drugs 23: 342-346, 2012.

29. Chen P, Fan Y, Man TK, Hung YS, Lau CC and Wong ST: A gene signature based method for identifying subtypes and subtypespecific drivers in cancer with an application to medulloblastoma. BMC Bioinformatics 14 (Suppl 18): S1, 2013.

30. He XM, Wikstrand CJ, Friedman HS, Bigner SH, Pleasure S, Trojanowski JQ and Bigner DD: Differentiation characteristics of newly established medulloblastoma cell lines (D384 Med, D425 Med, and D458 Med) and their transplantable xenografts. Lab Invest 64: 833-843, 1991.

31. Schroeder K and Gururangan S: Molecular variants and mutations in medulloblastoma. Pharmgenomics Pers Med 7: 43-51, 2014.

32. Gudrunardottir T, Lannering B, Remke M, Taylor MD, Wells EM, Keating RF and Packer RJ: Treatment developments and the unfolding of the quality of life discussion in childhood medulloblastoma: A review. Childs Nerv Syst 30: 979-990, 2014.

33. Duman JG and Forte JG: What is the role of SNARE proteins in membrane fusion? Am J Physiol Cell Physiol 285: C237-C249, 2003. 
34. Hiersemenzel K, Brown ER and Duncan RR: Imaging large cohorts of single ion channels and their activity. Front Endocrinol (Lausanne) 4: 114, 2013.

35. Jiménez-Garduño AM, Mitkovski M, Alexopoulos IK, Sánchez A, Stühmer W, Pardo LA and Ortega A: KV10.1 K(+)channel plasma membrane discrete domain partitioning and its functional correlation in neurons. Biochim Biophys Acta 1838: 921-931, 2014.

36. Mohrmann R, de Wit H, Connell E, Pinheiro PS, Leese C, Bruns D, Davletov B, Verhage M and Sørensen JB: Synaptotagmin interaction with SNAP-25 governs vesicle docking, priming, and fusion triggering. J Neurosci 33: 14417-14430, 2013.

37. Manca P, Mameli O, Caria MA, Torrejón-Escribano B and Blasi J: Distribution of SNAP25, VAMP1 and VAMP2 in mature and developing deep cerebellar nuclei after estrogen administration. Neuroscience 266: 102-115, 2014.

38. Ramakrishnan NA, Drescher MJ and Drescher DG: Direct interaction of otoferlin with syntaxin 1A, SNAP-25, and the L-type voltage-gated calcium channel Cav1.3. J Biol Chem 284: 1364-1372, 2009.

39. Xu J, Luo F, Zhang Z, Xue L, Wu XS, Chiang HC, Shin W and Wu LG: SNARE proteins synaptobrevin, SNAP-25, and syntaxin are involved in rapid and slow endocytosis at synapses. Cell Reports 3: 1414-1421, 2013

40. Woodbury DJ and Rognlien K: The t-SNARE syntaxin is sufficient for spontaneous fusion of synaptic vesicles to planar membranes. Cell Biol Int 24: 809-818, 2000.

41. Bühren J, Christoph AH, Buslei R, Albrecht S, Wiestler OD and Pietsch T: Expression of the neurotrophin receptor p75NTR in medulloblastomas is correlated with distinct histological and clinical features: Evidence for a medulloblastoma subtype derived from the external granule cell layer. J Neuropathol Exp Neurol 59: 229-240, 2000.

42. Südhof TC and Rizo J: Synaptic vesicle exocytosis. Cold Spring Harb Perspect Biol 3: a005637, 2011.

43. Fatemi SH, Earle JA, Stary JM, Lee S and Sedgewick J: Altered levels of the synaptosomal associated protein SNAP-25 in hippocampus of subjects with mood disorders and schizophrenia. Neuroreport 12: 3257-3262, 2001.

44. Thompson PM, Egbufoama S and Vawter MP: SNAP-25 reduction in the hippocampus of patients with schizophrenia. Prog Neuropsychopharmacol Biol Psychiatry 27: 411-417, 2003.

45. DeSouza RM, Jones BR, Lowis SP and Kurian KM: Pediatric medulloblastoma - update on molecular classification driving targeted therapies. Front Oncol 4: 176, 2014.

46. Selak S, Paternain AV, Aller MI, Picó E, Rivera R and Lerma J A role for SNAP25 in internalization of kainate receptors and synaptic plasticity. Neuron 63: 357-371, 2009.
47. Lesch KP and Schmitt A: Antidepressants and gene expression profiling: How to SNARE novel drug targets. Pharmacogenomics J 2: 346-348, 2002.

48. Hamdan FF, Piton A, Gauthier J, Lortie A, Dubeau F, Dobrzeniecka S, Spiegelman D, Noreau A, Pellerin S, Côté M, et al: De novo STXBP1 mutations in mental retardation and nonsyndromic epilepsy. Ann Neurol 65: 748-753, 2009.

49. Hussain S: Developing a PPI inhibitor-based therapy for STXBP1 haploinsufficiency-associated epileptic disorders. Front Mol Neurosci 7: 6, 2014.

50. Murmu RP, Li W, Holtmaat A and Li JY: Dendritic spine instability leads to progressive neocortical spine loss in a mouse model of Huntington's disease. J Neurosci 33: 12997-13009, 2013.

51. Northcott PA, Jones DT, Kool M, Robinson GW, Gilbertson RJ, Cho YJ, Pomeroy SL, Korshunov A, Lichter P, Taylor MD, et al: Medulloblastomics: The end of the beginning. Nat Rev Cancer 12: 818-834, 2012.

52. Perreault S, Ramaswamy V, Achrol AS, Chao K, Liu TT, Shih D, Remke M, Schubert S, Bouffet E, Fisher PG, et al: MRI surrogates for molecular subgroups of medulloblastoma. AJNR Am J Neuroradiol 35: 1263-1269, 2014.

53. Sengupta R, Dubuc A, Ward S, Yang L, Northcott P, Woerner BM, Kroll K, Luo J, Taylor MD, Wechsler-Reya RJ, et al: CXCR4 activation defines a new subgroup of Sonic hedgehog-driven medulloblastoma. Cancer Res 72: 122-132, 2012

54. Zhang X, Cruz FD, Terry M, Remotti F and Matushansky I: Terminal differentiation and loss of tumorigenicity of human cancers via pluripotency-based reprogramming. Oncogene 32: 2249-2260, e1-21, 2013.

55. Snuderl M, Batista A, Kirkpatrick ND, Ruiz de Almodovar C, Riedemann L, Walsh EC, Anolik R, Huang Y, Martin JD, Kamoun W, et al: Targeting placental growth factor/neuropilin 1 pathway inhibits growth and spread of medulloblastoma. Cell 152: 1065-1076, 2013.

56. Hodel A: Snap-25. Int J Biochem Cell Biol 30: 1069-1073, 1998.

57. Liu J, Guo L, Jun-Wei L, Liu N and Li H: All-trans retinoic acid modulates fas expression and enhances chemosensitivity of human medulloblastoma cells. Int J Mol Med 5: 145-149, 2000.

58. Ruggiero A, Conter V, Milani M, Biagi E, Lazzareschi I, Sparano P and Riccardi R: Intrathecal chemotherapy with antineoplastic agents in children. Paediatr Drugs 3: 237-246, 2001.

59. Hudson TJ: Genome variation and personalized cancer medicine. J Intern Med 274: 440-450, 2013.

60. Sreenivasan Y, Sarkar A and Manna SK: Mechanism of cytosine arabinoside-mediated apoptosis: Role of Rel A (p65) dephosphorylation. Oncogene 22: 4356-4369, 2003 